part which the technical colleges might take in research. Private firms, however, must continue increasingly to carry out scientific work for themselves, and increasing numbers of their technical staff will require a more scientific training; and he stressed the need for planning so as to ensure that research work is at all times adequately prosecuted undisturbed by fluctuations in the prosperity of the industry. Commenting on the special problems of Scottish heavy industry, Mr. Marshall emphasized its comparative isolation from other industrial areas, the lack of variety of technical facilities, and of the skilled manpower and brain-power provided by light industry. It is thus the more important that the industry should make the fullest use of existing technical facilities. After reviewing the functions of an industrial research department, including the necessity of keeping abreast of research and development work elsewhere, and the qualifications of its staff, he briefly outlined the problems with which the research department of Messrs. Babcock and Wilcox, Ltd., is concerned. No section is entirely devoted either to routine or to research, and physics is of increasing importance in almost every branch of technology.

At the afternoon session, which considered broadly the balancing of Scotland's industries, Dr. J. W. McDavid reviewed the experience of the Explosives Division of Imperial Chemical Industries, Ltd., with nitrocellulose finishes, 'Cellofas', ethylcellulose, pentaerythritol, 'Ardil', etc., to indicate the way in which a live research and development department leads to new manufactures loosely but logically connected with the main industry. Dr. W. M. Cummings' paper, "Chemical Research for Scottish Industry", considered especially the needs of the small manufacturer who is characteristic of the region. The region is not big enough industrially to have several different research organisations, and while Dr. Cummings referred to the idea of establishing a research organisation in Scotland, working in close association with the Department of Scientific and Industrial Research, covering all branches of industry, engineering, building, coal, food, etc., he appeared to look rather to the technical colleges for greater assistance, and in particular he commended the example of the Joint Research Council established in Manchester. The idea could be extended with advantage in other areas, and should promote the contacts between industry and the technical colleges and universities which are all-important.

Mr. J. N. Toothill, discussing "Research in the Light Engineering Industries", commented on the effect of research and development on export policy and its assistance in securing balanced employment. It also helps to raise the standard of living of the community, and it can be an important factor in determining the location of industry. Mr. Toothill dealt with this idea in some detail, suggesting that in a new light industry, the growth of new products arising out of technical discoveries and appreciation of their market possibilities, and communications with market centres and centres of research, are more important influences on the location of industry than the supply of cheap raw material, adequate modern factory facilities and adequate, cheap and reliable supplies of electric power. At present, Scotland employs only $2 \cdot 5$ per cent of the total scientific man-power of the United Kingdom, as against a working population of 10 per cent, and new industries fail to grow in all areas distant from London. In this connexion, he referred to the tendency in the
United States, and to some extent in Great Britain, to segregate the direction of policy, market research and technical research in areas near the national headquarters, leaving production to be carried out where labour is available.

In the final paper of the Conference, Prof. R. Hay, reviewing the individual Scottish firm and its application of research, pointed out that the first essential is a desire on the part of firms to utilize the advances already made in technical research. For small firms he suggested first the engagement of a professional consultant. For larger firms a technical development officer might be employed as technical adviser to the head of the firm, working in conjunction with established research associations, possibly supplemented by a small staff of his own. To meet the dearth of qualified men a co-operative effort of technical colleges and industry would be required, while finally Prof. Hay urged that industry in Scotland could with advantage develop a research centre on the lines of the Mellon Institute.

\section{EMISSION OF RADIO-WAVES BY THE GALAXY AND THE SUN}

\section{BY JOSEPH S. SHKLOVSKY}

Sternberg Astronomical Institute of the Moscow State University

1 HE remarkable investigations of Reber', Southworth $^{2}$ and Appleton ${ }^{3}$ have shown that radiowaves in the metre and centimetre region are emitted by the galaxy and the sun. Henyey's and Keenan's theory of long-wave emission by the galaxy ${ }^{4}$ is based on the assumption that the mechanism of this emission is a free-free emission from interstellar gas. However, they have not correctly accounted for the absorption of radio-waves in the galaxy. Besides free-free absorption (which Henyey and Keenan took into account), there is an ordinary absorption of radio-waves because of damping oscillations of electrons in the field of radio-waves. The coefficient of absorption is given by

$$
\alpha_{y}=\frac{\pi e^{2} N_{e}}{m} \cdot \frac{1}{c} \frac{\gamma}{4 \pi v^{2}+(\gamma / 2)^{2}} .
$$

In interstellar space (and even more so in the solar atmosphere) the constant of damping $\gamma$ is determined by the collision of electrons with ions. In this case

$$
\gamma=4 N_{i} \sqrt{\frac{2 \pi k T_{\varepsilon}}{m}} \cdot \frac{\pi}{2} \frac{e^{4}}{\left(k T_{\varepsilon}\right)^{2}} \ln \left(\frac{3}{2} \frac{k T_{\varepsilon}}{\left.e^{2} N_{e}\right)^{1 / 3}}\right),
$$

where $N_{i}=N_{e}$, the concentration of ions, and $T_{\varepsilon}$ is the electron temperature.

Solving the equation of transfer, we get the following expression for the intensity of galactic radioemission :

$$
I_{\nu}=\frac{2 \nu^{2} k T_{\varepsilon}}{c^{2}}\left(1-e^{-\tau_{v}}\right)
$$

where $\tau_{v}$ is the optical depth of the galaxy in a given direction. Here the coefficient of absorption is accounted for in the above-mentioned manner.

Each intensity of a given optical depth of the galaxy in a given direction measured by Reber can be brought to a mutual correspondence. Assuming that $T_{\varepsilon}=10,000^{\circ}$, we find that the above-mentioned $\tau_{\nu}$ changes from $\mathbf{0 . 4 8}$ (in Sagittarius, where the intensity is the highest) to 0.008 (in Perseus). For most regions of the Milky Way $\tau_{\nu}$ is less than $0 \cdot 1$. 
Eddington and, in more detail, Strømgren showed ${ }^{5}$ that interstellar hydrogen is ionized in the so-called zones of ionized hydrogen which surround the hot stars. According to Strømgren, the ratio of the volume of the zones of ionized and unionized hydrogen is $1 / 9$. In the zones of ionized hydrogen $N_{e}$ is ${ }^{6}$ of the order of $2-4 / \mathrm{cm} .^{3}$; in the zones of unionized hydrogen $N_{e}$ is at least a hundred times smaller. Therefore, the zones of unionized hydrogen practically do not have any influence on the long-wave emission of the galaxy, as their optical depth is negligibly small. If the above-mentioned estimation of the ratio of both zones were correct, $\tau_{v}$ would be much larger in all directions in the galaxy than those determined by Reber.

It can be supposed that the volume of the zones of ionized hydrogen given by Strømgren is too large. Strømgren extrapolated the relative number of hot stars observed in the vicinity of the sun to the whole galaxy. However, according to Baade? hot stars belong to the so-called 'first type' of population of the galaxies and are found only on the borders of the latter.

The optical depth of the solar atmosphere for radio-waves of different wave-length can be calculated. The optical depth of the chromosphere for $\lambda=1 \mathrm{~cm}$. is $3 \times 10^{3}$; for $\lambda=10 \mathrm{~cm}$., it is $3 \times 10^{5}$; and for $\lambda=187 \mathrm{~cm}$., it is $10^{8}$. Therefore, the chromosphere is not transparent for radio-waves. The optical depth of the corona for the same wavelengths is correspondingly $1.2 \times 10^{-4}, 0.013$ and 4.5 , assuming that the electron temperature of the whole corona $T_{\varepsilon}=350,000^{\circ}{ }^{8}$. Therefore, the radiation in the centimetre range observed by Southworth is emitted mainly by the top layers of the chromosphere, that of the metre region (Reber) by the corona. However, if the temperature of the electrons of the whole corona were equal to $350,000^{\circ}$, the radio emission would be at least one hundred times larger than that measured by Reber. In order to bring theory and observations into accordance, it is necessary to assume that the electron temperature of the outer corona is relatively low and equal to about $3,500^{\circ}$. In this case the optical depth of the outer corona $\left(R / R_{\odot}>3\right)$ will be equal to $4 \cdot 6$. The outer corona will absorb intensely the radio emission of the 'hot' inner corona ; its own emission will correspond to low temperature.

Recently Appleton ${ }^{3}$ ascertained that at times the sun emits radiation $7 \mathrm{~m} .<\lambda<30 \mathrm{~m}$., the intensity of which is at least $10^{4}$ times more than the intensity of a black body at $T=6,000^{\circ}$. He connects this with bright eruptions in the solar atmosphere. This phenomena evidently could not take place if the emitter were a black body.

We suppose that in this case the proper vibrations of the plasma of the outer corona are the cause of radiation. This is based on the astonishing coincidence of the frequency of proper vibrations of the plasma given by Langmuir's formula:

$$
\omega_{L}=\sqrt{\frac{4 \pi e^{2} N_{e}}{m}}
$$

with that observed by Appleton's fellow-workers. Linder ${ }^{9}$ showed that it was possible for longitudinal waves to be propagated in the plasma with a frequency close to $\omega L$. Every vibrating electron will emit radiation of frequency $\omega_{L}$. This phenomena was observed by Penning ${ }^{10}$, Ditmer ${ }^{11}$ and others.

Proper vibrations of plasma may be caused by a flow of charged corpuscles, which move through the corona with a velocity more than that of sound. This was observed experimentally by Merill and $W_{e b b}{ }^{12}$; Vlasov ${ }^{13}$ worked out a theory explaining the loss of energy of charged particles through their exciting proper vibrations. If the concentration of fast corpuscles necessary for exciting vibrations of the observed power is calculated, taking this theory as a basis, the derived values are fully reasonable.

If the proposed theory is correct, there must be a magnetic storm about one day after the outburst of the anomalous radio emission. After the above was written, I learned that this had been observed ${ }^{\mathbf{1 4}}$. Another result of this theory is that the sun should emit, to a great extent, radiations in the decimetre range caused by proper vibrations of the plasma of protuberances and upper chromosphere. The corona only slightly absorbs this radiation. The 'decimetre' and 'metre' radiations should arise almost simultaneously. Entirely new possibilities for predicting geophysical phenomena are therefore revealed.

Details of this investigation are given in the Russian Astronomical Journal, 23, No. 6, 333.

${ }^{1}$ Astrophys. J., 100, 279 (1944).

${ }^{2} J$. Franklin Inst., 239, 285 (1945).

3 Nature, 156, 635 (1945).

${ }^{4}$ Astrophys. J., 91, 625 (1940).

s Astrophys. J., 89, 526 (1939).

'Astrophys. J., 88. 364 (1939): 89, 119 (1939).

7 Astrophys. J., 100, 137 (1944).

${ }^{8}$ Z. Astrophys., 3, 199 (1933).

- Phys. Rev., 49, 753 (1936).

${ }^{10}$ Physica, 6, 241 (1926).

${ }^{11}$ Phys. Rev., 28, 507 (1926).

${ }_{12}$ Phys. Rev., 55, 1191 (1939).

${ }^{13}$ Sci. Letters Moscow State Univ., 75 (1945).

14 Nature, 15\%, 46, 48 (1946).

\section{FORTHCOMING EVENTS}

(Meeting marked with an asterisk * is open to the public)

\section{Monday, June 2}

UNIVERSITY COLLEGE, LONDON (at the Institution of Electrical Engineers, Savoy Place, Victoria Embankment, London, W.C.2), at 5.30 p.m.- Prof. R. O. Kapp: "The Presentation of Technical'Information" (other lectures will be given on June 9, 16 and 23).*

Tuesday, June 3

ROYAL ANTHROPOLOGICAL INSTITUTE (at 21 Bedford Square, London, W.C.1), at 5.30 p.m.-Rev. W. J. Culshaw : "The Santals of Western Bengal".

Wednesday, June 4 PHYSICAL Socuetr, Colour GRouP (at the Lighting Service Bureau,
E.L.M.A., 2 Savoy Hill, London, W.C.2), at 3.30 p.m.-Mr. H. G. W. Harding: "The Colour Temperature of Light Sources". INSTITUTE OF PETROLEUM (at the Royal Institution, 21 Albemarle
Street, London, W.1), at 5.30 p.m.-Mr. R. P. Russell: Second CadStreet, London, W.1), at
man Memorial Lecture.

Society OF ChEMical INDUSTRY, NUTRITION PANEL (at the Chemical Society, Burlington House, Piccadilly, London, W.1), at 6.30 p.m.Dr. Magnus Pyke: "Nutrition in Post-War Germany and Austria" (members of the Food Group are invited).

Thursday, June 5

FEDFRation OF BRITISH INDUSTRIES (at the Royal Victoria Hotel, Sheffield), at 10 a.m.-Regional Conference on "Industry and Research".

RoYAL SocIETY (at Burlington House, Piccadilly, London, W.1), at 4.30 p.m.- Sir Thomas Merton, F.R.S.: "On Interference Micro" scopy"; Dr. S. Tolansky and Mr. W. L. Wilcock: "Interference Studies of Diamond Faces-A Crossed Fringe Technique".

Chemical Societr (at Burlington House, Piccadilly, London, W.1), at 7.30 p.m.- Scientific Papers.

Friday, June 6 SOCIETY OF CHEMICAL INDUSTRY, FOOD GRoup (joint meeting with
the ROYAL SANITARY INSTITUTE, at the Torquay Natural History the ROYAL SANITARY INSTITUTE, at the Torquay Natural History
Museum, Babbacombe Road, Torquay), at 10 a.m.- Discussion on
"The Microbiological Aspects of Food. Quality" (to be opened by Prof. H. D. Kay, F.R.S.). (Meeting will constitute the Food and Prof. H. D. Kay, F.R.S.). (Meeting will
Nutrition Section of the Health Congress.)

INSTITUTION OF THE RUBBER INDUSTRY (at the Connaught Rooms, Great Queen Street, London, W.C.2), at 5.30 p.m.-Dr. Philip Schidrowitz: "The Impact of Synthesis on the Rubber Industry" (Second Foundation Lecture). 